\title{
O Discurso de Ódio e o Fascismo na Sociedade Brasileira: uma Análise a Partir do Pensamento de Wilhelm Reich
}

\section{Hate Speech and Fascism in Brazilian Society: an Analysis from Wilhelm Reich's Thought}

\author{
Marcio Notari
}

Universidade do Oeste de Santa Catarina, Programa de Pós-Graduação Stricto Sensu em Direitos Fundamentais. SC, Brasil.

E-mail: marciobnotari@gmail.com

\begin{abstract}
Resumo
A Psicologia de Massas e do Fascismo (1932) é uma obra que tem como discussão elementar em saber o que impede a correspondência saudável entre a situação econômica e a estrutura psíquica dessas massas populares. Qual a essência da estrutura psicológica das massas e a sua relação com a base econômica da qual se origina? O autor partindo dessa premissão busca refletir sobre questões ligadas aos aspectos morais, políticos, sociológicos e psicológicos para esclarecer a adesão e o comportamento das massas diante do movimento fascista, a partir de seus conhecimentos clínicos sobre a estrutura do caráter humano no cenário político e social. A intenção é demonstrar nas linhas que se seguem, como os elementos economicos não tem influência sobre as massas, em sentido contrário ao pensamento marxista, cuja idéia central era que a fome e a miséria (teoria economica do socialismo) levaria as massas proletárias ao processo revolucionário de ruptura com o capitalismo. No pensamento Reichiano, em contraponto as idéias de Marx, o autor busca demonstrar que o movimento facista e o nacional socialismo alemão, em especial, seria a expressão da estrutura de caráter irracional do homem médio, cujos impulsos sexuais foram reprimidos tendo analisado o papel da família e da igreja como misticismo organizado no campo da sociedade. Reich entende que a existência humana seria determinada não apenas pelos processos econômicos, mas também pelos processos institivos dos seres humanos determinados no ambito da família autoritária, cuja figura do pai, representa a ideia de autoridade, e por outro lado, a ideia de nação e pátria mãe, está configurada na figura da mãe paterna, protetora dos filhos. Desse modo, na psicologia política de Reich, o que se estuda é o fator subjetivo da história, a estrutura do caráter do homem numa determinada época e a estrutura ideológica da sociedade que ela forma. Será analisado essas premissas são aplicadas na sociedade brasileira, buscando compreender o fascismo e o discurso de ódio.
\end{abstract}

Palavras-chave: Discurso de Ódio. Psicologia de Massas. Sociedade Brasileira.

\begin{abstract}
The Psychology of the Masses and Fascism (1932) is a work that has the elementary discussion of knowing what prevents the healthy correspondence between the economic situation and the psychic structure of these popular masses. What is the essence of the psychological structure of the masses and its relation to the economic base from which it originates? Based on this premise, the author seeks to reflect on issues related to moral, political, sociological and psychological aspects to clarify the adhesion and behavior of the masses towards the fascist movement, based on their clinical knowledge about the structure of human character in the political and social scenario. . The intention is to demonstrate in the following lines, how the economic elements have no influence on the masses, in a sense contrary to Marxist thought, whose central idea was that hunger and misery (economic theory of socialism) would lead the proletarian masses to the process revolutionary break with capitalism. In Reichian thought, in contrast to Marx's ideas, the author seeks to demonstrate that the facist movement and the German national socialism, in particular, would be the expression of the irrational character structure of the average man, whose sexual impulses were repressed having analyzed the role of family and church as organized mysticism in the field of society. Reich understands that human existence would be determined not only by economic processes, but also by the institutional processes of human beings determined in the context of the authoritarian family, whose father figure represents the idea of authority, and on the other hand, the idea of nation and mother country, is configured in the figure of the paternal mother, protector of the children. Thus, in Reich's political psychology, what is studied is the subjective factor of history, the structure of man's character at a given time and the ideological structure of the society it forms. These premises will be analyzed and applied in Brazilian society, seeking to understand fascism and hate speech.
\end{abstract}

Keywords: Hate Speech. Mass Psychology. Brazilian Society.

\section{Introdução}

Para que se possa compreender a questão do fascismo em Wilhelm Reich (1897-1957) é necessário, preliminarmente, mencionar o surgimento de sua proposta acerca da discussão envolvendo o tema da psicologia de massas e do fascismo em suas premissas teóricas e fatuais. O debate tem como pano de fundo os eventos ocorridos na década de 30, em especial na Alemanha, dentre eles, em particular, a ascensão e, por consequência, a tomada do poder pelo nacional socialismo (1933), em que o fascismo torna-se um fenômeno internacional e como analisa o caráter do homem e seu envolvimento pelo fascismo.

Apesar do contexto político dos anos 30, o autor inicia o texto mencionando a primavera o contexto da ascensão do movimento nacional socialista alemão, o qual após a ruptura 
com seu mentor Freud, teria mudado para Berlim, onde viveu de 1930 a 1933. Filia-se ao partido comunista alemão e envolve-se de forma intensa com a política e a psicanálise, tentando unir as ideias de Marx com as Freudianas, tendo em vista a preocupação com o avançar do nazismo e com o interesse das pessoas na ideologia. Para Reich estas experiências possibilitariam o repensar não só do movimento de massas enquanto classe trabalhadora e política, mas também das ideias comunistas.

$\mathrm{O}$ autor busca pensar o fenômeno de massas a partir da relação entre política e sexualidade, dirigindo-se especialmente aos jovens e ao operariado, uma vez que sua preocupação estava focada na ascensão e a adesão crescente das massas as ideias de Hitler e ao totalitarismo, utilizando para isso, dos seus conhecimentos clínicos, numa relação harmônica entre a teoria marxista revolucionária com a vida psíquica enquanto fator subjetivo (Freud), numa perspectiva da psicologia política, sem excluir ambos referenciais teóricos, abordando as questões do instinto humano. .

Dessa forma, Reich traça os aspectos relevantes sobre o tema: ele afirma que não seria a miséria, a fome e as condições econômicas e de trabalho que conduziriam as massas ao um processo de ruptura com o capital. A ideologia das massas não coincide necessariamente com a situação econômica em que vivem, não traduzindo necessariamente em uma consciência política. Sendo assim, poderá haver, nesse caso, uma divisão entre a situação no campo social e a consciência social.

Nesse sentido, para compreensão da psicologia de massas e do fascismo, na sociedade brasileira, utilizarmos a ideias que Reich denota em seu contexto a ideia de entender o seio da família autoritária, a inibição moral nos primeiros anos de vida, o papel e a função da igreja, na fase adulta; a educação autoritária são elementos de opressão que impedem e escravização das massas humanas, que contribuem para as fortes tendências autoritárias e moralistas no desenvolvimento social, independente dos chavões políticos. Ou seja, o fator emotivo é determinante na psicologia das massas e da constituição do Estado autoritário.

\section{Desenvolvimento}

\subsection{Metodologia}

O método adotado para a realização do trabalho é de natureza bibliográfica foi o dedutivo, tendo pressuposto argumentos gerais, para argumentos particulares; quanto ao procedimento será analítico e o histórico crítico, procurando dar tratamento localizado à matéria objeto de estudo no qual os conceitos que realizam a interseção entre o Direito e a
Pscicanálise Reichiana que serão investigados para que se sejam conhecidos, permitindo destacar seus pontos centrais e imprescindíveis tanto para a Filosofia do Direito, quanto para os direitos humanos e fundamentais.

\subsection{Fundamentos Teóricos e Factuais da Psicologia das Massas}

A palavra fascismo possui diversos significados no seu termo. O primeiro deles, em sua questão histórica específica, faz menção ao fascismo italiano; já em relação ao segundo possui uma dimensão internacional do movimento fascista, quando houve a consolidação do nacional-socialismo (nazismo), na Alemanha em razão de suas características ideológicas (critérios de organização, fins políticos, sendo chamado por analogia de fascismo alemão); e o terceiro, estende o termo a todos os movimentos ou regimes que compactuam com a definição de "Fascismo histórico" (BOBBIO, 1999, p.415)

Nesta última acepção, segundo o jurista italiano, o fascismo assumiu faces indefinidas, que tornaram dificil sua utilização ao menos em termos e propósitos cientificos ${ }^{1}$. Assim, acentuando-se a tendência de restringir seu uso apenas ao Fascismo histórico (1919 - 1945), o qual está representado em suas características nos dois movimentos: o fascismo italiano e o nacional-socialismo alemão.

Arendt (2013) já alertava, a que mesmo diante de duas guerras mundiais em uma geração, separadas por uma série ininterrupta de guerras locais e revoluções, seguidas de nenhum tratado de paz para os vencidos e de nenhuma trégua para os vencedores, levaram à antevisão de uma terceira guerra mundial entre as duas potências que ainda restavam. $\mathrm{O}$ momento de expectativa é como a calma que sobrevém quando não há mais esperança. Já não ansiamos por uma eventual restauração da antiga ordem do mundo com todas as suas tradições, nem pela reintegração das massas, arremessadas ao caos produzido pela violência das guerras e revoluções e pela progressiva decadência do que sobrou. A autora elenca que a civilização chegou ao seu processo de ruptura, em face da imprevisibilidade da evolução do século XX, e a ausência de explicação adequada para os horrores ocorridos em face da questão judaica e o antissemitismo se transformaram em catalisador, primeiro, o movimento nacional socialista (nazimo); segundo, de uma guerra mundial; e, ao final, da construção dos centros fabris de morte em massa (campos de concentração). Verificamos nos conceitos explicitados anteriormente a questão das massas como elemento nesses contextos históricos e políticos, as quais estão diretamente relacionadas ao âmbito da política, das guerras, da economia, do espaço público e dos movimentos de massa (Nazismo,

1 Por seu alto teor explosivo, a palavra "fascista" tem sido frequentemente usada como arma na luta política. É compreensível que isso ocorra. Para efeito de agitação, é normal que a esquerda se sirva dela como epíteto injurioso contra a direita. No entanto, esse uso exclusivamente agitacional pode impedir a esquerda, em determinadas circunstâncias, de utilizar o conceito com o necessário rigor científico e de extrair do seu emprego, então, todas as vantagens políticas de uma análise realista e diferenciada dos movimentos das forças que lhe são adversas. Nem todo movimento reacionário é fascista. Nem toda repressão - por mais feroz que seja - exercida em nome da conservação de privilégios de classe ou casta é fascista. O conceito de fascismo não se deixa reduzir, por outro lado, aos conceitos de ditadura ou de autoritarismo (KONDER, 2009). 
Fascismo e o Stalinismo) ${ }^{2}$.

Muitos ainda julgam que a ideologia nazista girou em torno do antissemitismo por acaso, e que desse acaso nasceu a política que inlexivelmente visou perseguir e, ao final, exterminar os judeus. O horror do mundo diante do resultado constituído pelos sobreviventes sem lar e sem raízes, dando proeminencia a questão judaica (em termos de política e perseguição em nível mundial), como "truque demagógico para conquistar as massas" (ARENDT, 2013, p.15).

Nesse sentido, caberia o seguinte questionamento: como as massas aderiram a esse movimento imposto pelo terror e pelo medo, exterminando pessoas na lógica dos campos de concentração, promovendo as atrocidades desde experimentos médicos com crianças e jovens, até o uso de mão de obra escrava, as câmaras de gás e a eliminação sem precedentes em razão do critério da raça? A teoria Reichiana, destaca que:

Uma característica dos discursos nos comícios nacionalsocialistas era a habilidade em manejar as emoções dos indivíduos e evitar qualquer argumentação objetiva. Hitler apontou que a tática certa na psicologia de massas era prescindir da argumentação, apontando às massas apenas o objetivo final. Mas a história pessoal de Hitler e a sua estrutura emocional não são relevantes para a compreensão do nacional-socialismo. O que importa é saber o motivo pelo qual as massas se deixam iludir politicamente, porque se tornam receptivas ao embotamento. A inibição sexual é o elo de ligação à família autoritária. $\mathrm{O}$ vínculo biológico original da criança com a mãe e vice-versa leva a uma fixação indissolúvel e a uma incapacidade de estabelecer novas relações emotivas. A base dos vínculos familiares é o vínculo com a mãe (REICH, 2001, p.15)

Ou seja, uma vez fixada a ligação do inconsciente com a mãe, a ligação com a família e o sentimento nacionalista passam a ser um produto social. A base desse sentimento de ligação para com a mãe, do sentimento nacionalista do adulto, será o elemento determinante na constituição e transformação numa força social reacionária. Nesse sentido, a moralidade fascista tem por finalidade criar a submissão dos indivíduos, para que assim se adaptem à ordem autoritária. Essa estrutura autoritária do homem será produzida pela repressão dos impulsos sexuais (fixação das inibições e medos sexuais).

Ao definir sua posição Reich (2001) afirma que, a esposa conservadora do trabalhador passa tantas privações quanto a trabalhadora liberada, mas vota no partido fascista. Para o autor, a inibição moral seria fator impeditivo a conservadora de conseguir ter consciência de sua real situação social e pelas fortes ligações com a igreja e a religião. Entretanto, que haja a presença do estado autoritário na "psicologia das massas", a existência da autoridade do pai é imprescindível.

Isso porque, na visão Reichiana, cada componente do grupo familiar precisa reproduzir a lógica do pai, em regra, os filhos e a esposa, numa total submissão a autoridade (com fortes repressões e limitações sexuais), numa relação emocional que irá transcender o âmbito familiar. Decorre disso, a passividade e a obediência, que irão a figura do Fuher nacionalista como sendo a personificação da "nação familiar" e a encarnação o sentimento nacional das massas de submissão (REICH, 2001, p.17)

Entretanto, para que haja a adesão de forma submissa o indivíduo de massa, a submissão a autoridade patriarcal em conjunto com a religião, especialmente, em épocas de crise "as ditaduras" procuram reforçar a propaganda com forte carga em favor da moralidade, da consolidação do casament e da entidade familiar, em razão dos interesses da classe dominante $^{3}$ em manter a moralidade da classe média baixa, pois para o autor essa classe não perder a atitude moralista, o que estaria vinculado ao aspecto sexual. Sendo assim, vale citar os ensinamentos de Reich (2001, p.16):

A religião é incutida na criança na primeira infância. A ideia de Deus é associada ao pai e à mãe. Quem não respeita o pai comete um pecado, ou seja, quem se entrega ao prazer sexual (masturbação infantil) é castigado, pois Deus vê tudo. Assim a criança tem que ser boazinha mesmo na ausência dos pais. Essas inibições e fraquezas sexuais que são os prérequisitos para a existência da família autoritária são mantidas pela religião, que incute no indivíduo o sentimento de culpa sexual. Há uma relação estreita entre religião e negação do desejo sexual. A fraqueza sexual vai diminuir a autoconfiança. A compulsão para manter o recalcamento sexual provoca o desenvolvimento de concepções patológicas de honra e dever.

Levando em conta, essas ideias, para Reich, uma das principais concepções políticas do nacional socialismo e do seu antissemitismo na Alemanha, foi o medo irracional da sífilis. Consequentemente a pureza da raça era a pureza do sangue, segundo a teoria da raça ariana alemã e o eixo de sua ideologia fascista ${ }^{4}$, tanto que era para melhoramento das

2 Para Hannah Arendt, o totalitarismo é uma forma de governo e de dominação, baseado na organização burocrática de massas, no terror e na ideologia, provou, com o genocídio, não existirem limites a deformação da natureza humana. Para a autora, o totalitarismo apareceu tanto como um desdobramento da utopia capitalista, quanto da utopia socialista, conforme suas vertentes nazistas e stalinista (ARENDT, 2018).

$3 \mathrm{O}$ autor utiliza o termo numa clara alusão ao marxismo: Por burgueses entende-se a classe dos capitalistas modernos que são proprietários dos meios sociais de produção e utilizam o trabalho assalariado. Por proletários, a classe dos modernos trabalhadores assalariados que, não possuindo meios próprios de produção, dependem da venda de sua força de trabalho para sobreviver. Observação de Engels incluída na edição inglesa de 1888. (MARX;ENGELS, 2008). Para os autores a história da humandiade é marcada pelos antagonismos e a luta de classes.

4 De todas as perguntas não respondidas sobre nossa época, talvez a mais importante seja: “O que fascismo?”. Uma das organizações americanas de pesquisa social fez recentemente essa pergunta a cem pessoas diferentes e obteve respostas que foram desde "democracia pura" até "demonismo puro". Neste país, se se pedir a uma pessoa medianamente esclarecida que defina o fascismo, ela em geral responderá apontando os regimes alemão e italiano. Mas isso é muito insatisfatório, porque mesmo os grandes Estados fascistas diferem em boa medida um do outro em estrutura e em ideologia. Não é fácil, por exemplo, encaixar a Alemanha e o Japão num mesmo contexto, e isso é ainda mais difícil em relação a alguns dos pequenos Estados que se poderiam descrever como fascistas. Com frequência supõe-se, por exemplo, que o fascismo é inerentemente belicoso, que ele prospera num ambiente de histeria bélica e só pode resolver seus problemas econômicos mediante preparativos para a guerra ou conquistas no estrangeiro. Mas isso claramente não é verdadeiro no que tange, digamos, a Portugal ou a várias ditaduras sul-americanas. Ou, ainda, o antissemitismo é tido como uma das marcas distintivas do fascismo; mas alguns movimentos fascistas não são antissemitas (ORWELL, 2017) 
raças era proibido o cruzamento com outras raças, sob pena do declínio da raça superior. A própria suástica serviria como estimulo ao sentimento de ordem sexual.

Esses elementos também têm implicações no âmbito da família camponesa. Quando das eleições do Partido Nacional Socialista (1932), houve interesse dos grandes proprietários de terra. Mas, contudo, era preciso ganhar os pequenos e médios agricultores, sem que para isso fosse realizada uma defesa aberta dos interesses dos grandes proprietários. A ideologia fascista da organização hierárquica do Estado tem como modelo a organização hierárquica da família camponesa. Sendo essa uma nação em miniatura, a base para a absorção da ideologia imperialista está presente no campesinato e na classe média baixa (REICH, 2001).

Por outro lado, Marx preconizava que o primeiro passo da revolução dos trabalhadores é a ascensão do proletariado à situação de classe dominante, ou seja, a conquista da democracia. O proletariado utilizaria, conforme o víeis marxista, do seu predomínio político para retirada, de forma gradativa, de todo o capital da burguesia, com o fim de concentrar todos os instrumentos de produção nas mãos do Estado (proletariado organizado como classe). (MARX, 2008).

Nesse ponto, Wilhelm Reich vai tecer sua crítica, sem desconsiderar sua influência do marxismo, que não haverá correspondência do materialismo dialético marxista na relação entre a situação da economia e a consciência de classes, como sendo algo mecanizado, isto é, a situação produtiva material não determina a expressão de um ideal na consciência dos membros de uma classe social ${ }^{5}$.

A tese marxista de que o "material" (o existente) se transforma no "ideológico" (consciência) na mente humana, e não ao contrário, deixa duas questões por responder: a primeira é como acontece isto, o que acontece no cérebro do homem durante esse processo; a segunda refere-se aos efeitos dessa "consciência" assim adquirida (a partir daqui, falaremos de estrutura psíquica) sobre o processo econômico. Esta lacuna é preenchida pela psicologia baseada na análise do caráter, que estuda os processos da vida psíquica do homem, que por sua vez é determinada pelas condições da existência. Deste modo, tem-se em conta o "fator subjetivo", que o marxista comum não compreendeu. $\mathrm{O}$ objeto da psicologia política está, portanto, rigorosamente definido. Ela não pode, por exemplo, explicar a origem da sociedade de classes ou o modo de produção capitalista (e, se o tentar, os resultados serão inevitavelmente absurdos e reacionários, como o seria concluir que o capitalismo é consequência da cobiça humana). Mas só a psicologia política — e não a economia social — está em condições de estudar a estrutura do caráter do homem de determinada época, o seu modo de pensar, de agir, os efeitos que sobre ele exercem as contradições da sua existência, o modo como ele encontra soluções para a sua existência. Ela estuda apenas os homens e as mulheres individualmente. Quando existe uma especialização no estudo dos processos psíquicos típicos e comuns a uma categoria, classe, grupo profissional, etc., excluindo diferenças individuais, então temos a psicologia de massas. (REICH, 2001, p.36).

No período de rápido declínio da economia alemã (1929-1932) ${ }^{6}$, dá-se a grande ascensão do Partido NacionalSocialista, de 800000 votos em 1928 para 6.400 .000 no outono de 1930, 13 milhões no verão de 1932 e 17 milhões em janeiro de 1933. Segundo cálculos de Jaeger ("Hitler", Roter Aufbau, outubro de 1930), dos 6.400 .000 votos recebidos pelos nacional-socialistas, cerca de três milhões eram de trabalhadores, dos quais $60 \%$ a $70 \%$ eram empregados e $30 \%$ a $40 \%$, operários.

$\mathrm{O}$ autor salienta que onde existe uma clivagem entre a situação econômica e a ideologia, a questão central seria saber em que medida esses dois fatores, impedem a correspondência entre a situação econômica das massas e a sua estrutura psíquica. Assim, o foco de compreensão nessa ótica seria a essência da estrutura psicológica das massas e a sua relação com a base econômica originária. Sendo assim, a visão marxista é afastada parcialmente, no seu elemento econômico, o que representaria incompreensão do fascismo do ponto de vista da sua dinâmica ideológica.

A discussão vai além dos fatores econômicos e produtivos, o que o autor denomina de "efeito de volta" da ideologia, isto é, as formas pelas quais a ideologia incide sobre a própria base material que a determina. Como uma das respostas, é que esse fenômeno ocorre na vivência das instituições que formam as pessoas, em seu psiquismo: a primeira a família, a segunda a sexualidade e a terceira a sexualidade infantil na relação paifilho, e, por fim, o código moral no ser humano, não oriundo de origem divina e da igreja, mas da educação dada pelos pais e pelos seus representantes na infância.

\subsection{A Liberdade de Expressão na Constituição e nos Tratados de Direitos Humanos}

A Declaração dos Direitos do Homem e do Cidadão (1789), previa o exercício da liberdade de expressão e opinião, sem que houvesse a intervenção do Estado, em seu Art. 10. Ninguém deve ser perseguido por suas opiniões, mesmo religiosas, desde que sua manifestação não atrapalhe a ordem pública estabelecida pela lei. Art. $11^{\circ}$. A livre comunicação dos pensamentos e opiniões é um dos direitos mais preciosos

\footnotetext{
5 A ascensão de Hitler ao poder, na Alemanha, tornará insustentável a permanência de Reich no movimento psicanalítico, o qual buscará manter uma atitude de neutralidade em relação ao nazismo. Reich, exilado, escreverá Psicologia de massas do fascismo , brilhante obra de psicologia política - o calor da batalha não impediu a lucidez penetrante das análises -, na qual desmonta as teses economicistas do Partido Comunista, apontando os elementos psíquicos que fizeram com que o povo alemão se jogasse aos pés do Führer no momento de sua maior crise. (WEINMANN, 2002).

6 Enquanto assistia a ascensão do fascismo e a adesão crescente das massas às promessas de Adolf Hitler. Preocupado com o fenômeno, participava intensamente de movimentos de conscientização da população. Em 1933 o livro foi publicado pela primeira vez na Dinamarca, sendo reeditado no ano seguinte e traduzido para várias línguas. Cópias atravessaram as fronteiras alemãs e foram acolhidas por simpatizantes. Em 1935 foi proibido pelos fascistas na Alemanha. Em 1946 foi publicado pela primeira vez na Inglaterra. A atual edição brasileira é uma tradução da edição alemã, revista e confrontada com a última versão inglesa. (OLIVEIRA;CRUZ, 2009).
} 
do homem: todo cidadão pode, portanto, falar, escrever, imprimir livremente, embora deva responder pelo abuso dessa liberdade nos casos determinados pela lei .

Assim, o Declaração busca dar solução a relação governante e governado (o indivíduo singularmente considerado), titular do poder soberano (no hipotético estado de natureza pré-social), ainda inexistente acima dele. O poder político (poder dos indivíduos associados), será realizado após. Dessa inversão nasce o Estado moderno: liberal, no qual os indivíduos são apenas uma parte que reivindica o poder soberano; democrático, no qual são potencialmente todos a fazer tal reivindicação; e social, todos transformados em soberanos (indivíduos) sem distinções de classe, reivindicam, além dos direitos de liberdade, os direitos sociais. (BOBBIO, 2004).

O artigo $19^{\circ}$ da Declaração Universal Dos Direitos Humanos/DIDH (1948) diz que "todo o indivíduo tem direito à liberdade de opinião e de expressão, o que implica o direito de não ser inquietado pelas suas opiniões e o de procurar, receber e difundir, sem consideração de fronteiras, informações e ideias por qualquer meio de expressão".

O sistema internacional criou essa normativa internacional, pós-segunda guerra mundial, na qual os direitos humanos tiveram uma abordagem distinta. Isso porque, os regimes totalitários espalhados por vários países da Europa, levaram a um conflito imensurável, em níveis mundiais. Isso implica, também, que os direitos humanos não podem ser matéria exclusiva dos estados-membros, mas sujeitos ao controle internacional, trazendo a luz a ideia Kantiana, do direito a hospitalidade universal, do indivíduo sentir-se em casa no mundo.

Em relação ao elemento da publicidade e transparência, como condição para o exercício da liberdade de opinião e expressão, na visão de Imanuel Kant (2008, p.46), pode chamar-se à seguinte proposição a fórmula transcendental do direito público: "São injustas todas as acções que se referem ao direito de outros homens, cujas máximas se não harmonizem com a publicidade". Ou seja, a publicidade envolve o direito de todos fazerem o uso da razão pública de forma livre, constituindo uma ilustração dessa perspectiva iluministra contra o Estado absolutista e monárquico.

O Artigo 13 - Convenção Americana sobre Direitos Humanos 1. Toda pessoa tem direito à liberdade de pensamento e de expressão. Esse direito compreende a liberdade de buscar, receber e difundir informações e idéias de toda natureza, sem consideração de fronteiras, verbalmente ou por escrito, ou em forma impressa ou artística, ou por qualquer outro processo de sua escolha. Ainda elenca as seguintes previsões:

2. O exercício do direito previsto no inciso precedente não pode estar sujeito à censura prévia, mas a responsabilidades ulteriores, que devem ser expressamente previstas em lei e que se façam necessárias para assegurar: a) o respeito dos direitos e da reputação das demais pessoas; b) a proteção da segurança nacional, da ordem pública, ou da saúde ou da moral públicas.

3. Não se pode restringir o direito de expressão por vias e meios indiretos, tais como o abuso de controles oficiais ou particulares de papel de imprensa, de frequências radioelétricas ou de equipamentos e aparelhos usados na difusão de informação, nem por quaisquer outros meios destinados a obstar a comunicação e a circulação de ideias e opiniões.

4. A lei pode submeter os espetáculos públicos a censura prévia, com o objetivo exclusivo de regular o acesso a eles, para proteção moral da infância e da adolescência, sem prejuízo do disposto no inciso 2. 5. A lei deve proibir toda propaganda a favor da guerra, bem como toda apologia ao ódio nacional, racial ou religioso que constitua incitamento à discriminação, à hostilidade, ao crime ou à violência.

Como todo direito humano, o direito a liberdade de expressão é inalienável (não pode ser suprimido), e universal (inerente a todos seres humanos, sem exceção), bem como, indivisível e interdependente dos demais direitos humanos, eis que privação de um direito humano afeta demais direitos. Sendo assim, embora o direito de livre opinião, é importante observar os demais direitos, tais como, não ser atingindo na sua raça, cor, sexo, religião, idioma, origem social, posição econômica, ou qualquer outra condição social.

A Convenção dos Direitos da Criança (1989) também garante à criança o direito à liberdade de expressão, o qual inclui a liberdade de procurar, receber e divulgar informações e ideias de todo tipo, independentemente de fronteiras, de forma oral, escrita ou impressa, por meio das artes ou por qualquer outro meio escolhido pela criança (art. 13). Certas restrições podem ser impostas ao exercício de tal direito, mas unicamente se previstas em lei e se forem necessárias para o respeito dos direitos ou da reputação dos demais ou para a proteção da segurança nacional ou da ordem pública, ou da saúde e da moral públicas. Nesse item, vale frisar - é garantido as crianças o direito à liberdade de pensamento, de consciência e de crença.

É importante a menção aos tratados e convenções de Direitos Humanos, especialmente, a Convenção da ONU e da OEA, visto que se tratam de instrumentos normativos internacionais já ratificados pelo Brasil, anteriores a Emenda Constitucional 45/2004. Assim, já preceituava o Art. $5 \S 2$ da Constituição Federal, consagra de forma inédita, na Carta de 1988, segundo os ensinamentos de Piovesan (2013, p.112)

que os direitos e garantias expressos na Constituição "não excluem outros decorrentes do regime e dos princípios por ela adotados, ou dos tratados internacionais em que a República Federativa do Brasil seja parte.

Nesse sentido, é importante frisar que o discurso de ódio tem como base a auto afirmação que versa sobre a superioridade daquele que emite em relação a inferioridade de um determinado individuo, grupo, em virtude de alguns motivos, tais como, a raça, a cor, etnia nacionalidade, religião,

7 https://educacao.uol.com.br/disciplinas/historia/declaracao-dos-direitos-do-homem-e-do-cidadao-integra-do-documento-original.htm. 
cuja finalidade é propagar, divulgar, incitar, promover, ou ainda, justificar o ódio racional, a xenofobia lastreados na intolerância, que podem trazer consequências como a violência ou discriminação a estas pessoas (SILVA; SILVA, 2018). Há na visão das autoras a colisão da liberdade de expressão, nesse caso, em relação a outros direitos fundamentais.

Daí a oportunidade do estudo dos comportamentos e das realidades da vida que estão abrangidas no direito fundamental, tarefa que nem sempre se mostra simples, já que as normas de direitos fundamentais podem apresentar indeterminações semânticas e não ter o seu próprio suposto de fato bem delineado. Os problemas daí advindos podem ser ilustrados com questões cotidianas, como a de saber se o curandeirismo se inclui no âmbito da liberdade de culto ou se o discurso de ódio racial é protegido pela liberdade de expressão (MENDES, 2012).

A Constituição cogita da liberdade de expressão de modo direto no art. $5^{\circ}, \mathrm{IV}$, ao dizer "livre a manifestação do pensamento, sendo vedado o anonimato", bem como no inciso XIV do mesmo artigo, em que "é assegurado a todos o acesso à informação e resguardado o sigilo da fonte, quando necessário ao exercício profissional", e também no art. 220, quando dispõe que "a manifestação do pensamento, a criação, a expressão e a informação, sob qualquer forma, processo ou veículo não sofrerão qualquer restrição, observado o disposto nesta Constituição".

Acrescenta, nos $\S \S 1^{\circ}$ e $2^{\circ}$ do mesmo artigo, que "nenhuma lei conterá dispositivo que possa constituir embaraço à plena liberdade de informação jornalística em qualquer veículo de comunicação social, observado o disposto no art. $5^{\circ}$, IV, V, X, XIII e XIV", e que "é vedada toda e qualquer censura de natureza política, ideológica e artística.A especificidade do bem que o direito fundamental visa proteger conduz à revelação de limites máximos de conteúdo. É necessário proceder ao preciso enquadramento de uma dada conduta no sistema dos direitos fundamentais, para concluir pela sua proteção constitucional.

No que diz com a liberdade de pensamento e de expressão, conforme as lições de Sarlet (2019, p. 631),

a Constituição Federal de 1988 guarda sintonia com a evolução registrada, notadamente a contar da Declaração Universal dos Direitos Humanos da ONU, de 1948, no âmbito do direito internacional dos direitos humanos.

Assim, o livre exercício da liberdade de expressão e pensamento, sem qualquer censura prévia, todavia responsabilizados aqueles que fizerem uso abusivo (responsabilidade civil e penal), a medida que essas violações envolverem direitos a personalidade (honra, imagem, privacidade, etc), bem como, apologia ao ódio nacional, racial, religioso, incitação a violência e discriminação, uma vez que colidem com outros direitos humanos e fundamentais.

\subsection{O Discurso de Ódio na Sociedade Brasileira}

O discurso de ódio foi objeto de análise em momento anterior, pelo Supremo Tribunal Federal, nos autos do Habeas Corpus n. 82.424-2. Nesse caso, houve incitamento contra os judeus pelo jornalista Siefert Ellwanger, O crime está previsto no Art. 5, XLII, da CF, que elenca que a prática de racismo constitui crime inafiancável e imprescrítivel, sujeito a penas de reclusão nos termos da lei. (LAFER, 2005) ${ }^{8}$. Vale frisar que, a Constituição de 1988 reafirmou o comprometimento brasileiro de combate à discriminação racial ao dispor, no seu art. $4^{\circ}$, VIII, o repúdio ao racismo como um dos princípios que regem as relações internacionais brasileiras.

Ensina o autor que no caso do totalitarismo, adequarse às circunstâncias não significava ajustar-se a um mundo confiável, porque compartilhado por um sentido comum das coisas. Significava, dentre outros elementos, adaptar-se ao genocídio metódico e sistemático, conduzido de forma rigorosa dentro da ordem jurídica e dirigido, não contra inimigos, mas sim contra inocentes, que não eram sequer potencialmente perigosos, e tudo por razões não-utilitárias que escapavam a qualquer argumento de estado de necessidade (LAFER, 1988).

Em caso concreto, discutia-se a prática ou não de crime de racismo cometido por escritor e editor de livros por suposta discriminação contra os judeus (art. 5. ${ }^{\circ}$, XLII) ao pregar ideias antissemitas, preconceituosas e discriminatórias. Absolvido em primeira instância, a 3. ${ }^{\text {a }}$ Câmara Criminal do TJRS, por unanimidade, reformou a sentença e o condenou. Impetrado HC no STJ, a ordem foi denegada. Houve nova impetração de habeas corpus no STF, ora em análise (HC 82.424).

Para Gilmar Mendes (2015), por outro lado, o discurso de ódio, entre nós, não é tolerado. O STF assentou que incitar a discriminação racial, por meio de ideias antissemitas, "que buscam resgatar e dar credibilidade à concepção racial definida pelo regime nazista, negadoras e subversoras de fatos históricos incontroversos como o holocausto, consubstanciadas na pretensa inferioridade e desqualificação do povo judeu", constitui crime, e não conduta amparada pela liberdade de expressão, já que nesta não se inclui a promoção do racismo, devendo prevalecer os princípios da dignidade da pessoa humana e da igualdade jurídica.

Em suas conclusões, o Brasil, inclusive o nosso STF, não adotou o entendimento de que a garantia da liberdade de expressão abrangeria o hate speech. Ou seja, muito embora a "posição de preferência" que o direito fundamental da liberdade de expressão adquire no Brasil (com o seu

8 Com formação inicial na área de Direito Internacional Público, Celso Lafer é autor de diversos estudos e obras de cunho jurídico-filosófico, como Direito e Poder, tema abordado na perspectiva do pensamento de Miguel Reale. Na esfera filosófica, entre outros trabalhos, escreveu Hannah Arendt, Pensamento, Persuasão e Poder (1979). Sua obra principal e mais conhecida é A Reconstrução dos Direitos Humanos - Um diálogo com o pensamento de Hannah Arendt (1988), tese com a qual concorreu e obteve a titularidade na disciplina Filosofia do Direito, sucedendo a Miguel Reale na Universidade de São Paulo. (NADER, 2018). 
especial significado para um país que vivenciou atrocidades a direitos fundamentais durante a ditadura), assim como em outros países, a liberdade de expressão não é absoluta, encontrando restrições "voltadas ao combate do preconceito e da intolerância contra minorias estigmatizadas.

1. Escrever, editar, divulgar e comerciar livros 'fazendo apologia de ideias preconceituosas e discriminatórias' contra a comunidade judaica (Lei n. 7.716/89, art. 20, na redação dada pela Lei n. 8.081/90) constitui crime de racismo sujeito às cláusulas de inafiançabilidade e imprescritibilidade (CF, art. 5. $\left.{ }^{\circ}, \mathrm{XLII}\right)$. [...]. 10. A edição e publicação de obras escritas veiculando ideias antissemitas, que buscam resgatar e dar credibilidade à concepção racial definida pelo regime nazista, negadoras e subversoras de fatos históricos incontroversos como o holocausto, consubstanciadas na pretensa inferioridade e desqualificação do povo judeu, equivalem à incitação ao discriminem com acentuado conteúdo racista, reforçadas pelas consequências históricas dos atos em que se baseiam. [...]. 15. [...]. Jamais podem se apagar da memória dos povos que se pretendam justos os atos repulsivos do passado que permitiram e incentivaram o ódio entre iguais por motivos raciais de torpeza inominável. A ausência de prescrição nos crimes de racismo justifica-se como alerta grave para as gerações de hoje e de amanhã, para que se impeça a reinstauração de velhos e ultrapassados conceitos que a consciência jurídica e histórica não mais admitem (HC 82.424, Rel. p/ o ac. Min. Presidente Maurício Corrêa, j. em 17.09.2003, Plenário, DJ de 19.03.2004).

O Plenário do Tribunal, partindo da premissa de que não há subdivisões biológicas na espécie humana, entendeu que a divisão dos seres humanos em raças resulta de um processo de conteúdo meramente político-social. Desse processo, origina-se o racismo que, por sua vez, gera a discriminação e o preconceito segregacionista. Para a construção da definição jurídico-constitucional do termo "racismo", o Tribunal concluiu que é necessário, por meio da interpretação teleológica e sistêmica da Constituição, conjugar fatores e circunstâncias históricas, políticas e sociais que regeram a sua formação e aplicação.

Apenas desta maneira é possível obter o real sentido e alcance da norma, que deve compatibilizar os conceitos etimológicos, etnológicos, sociológicos, antropológicos e biológicos. Asseverou-se que a discriminação contra os judeus, que resulta do fundamento do núcleo do pensamento do nacional-socialismo de que os judeus e os arianos formam raças distintas, é inconciliável com os padrões éticos e morais definidos na Constituição do Brasil e no mundo contemporâneo, sob os quais se ergue e se harmoniza o Estado Democrático de Direito9.

O discurso do ódio, é denominado de hate speech, sendo considerado todo e qualquer discurso que pregue a intolerância, o ódio e a discriminação a determinados grupos ou minoriais. Trata-se de dicusro de intolerância com potencial catalisador do ódio nas sociedades democráticas. Esse tipo de discurso interefere na dignidade humama, na igualdade entre as pessoas, no regime democrático e nos valores que forma uma sociedade pluralista, diante das manifestações de ódio $\left(\right.$ SILVA, 2016) ${ }^{10}$. Essa terminologia acadêmica é de muito atual no Brasil e em diversos países no mundo, em face do discurso neonazista, antissemita, islamofóbico, entre outras manifestações de pensamento ligadas ao ódio.

No que tange ao contexto da liberdade de expressão e a prática do discurso de ódio, ou ainda, de incitação ao ódio (hate speech), na visão de Sarlet (2015) corresponde ao entendimento dominante, no Brasil e em geral no direito comparado, que a liberdade de expressão encontra limites na dignidade da pessoa humana de todas as pessoas e grupos afetados quando utilizada para veicular mensagens de teor discriminatório e destinadas a incitar o ódio e até mesmo a violência.

No campo dos direitos humanos, do Pacto Internacional de Direitos Civis e Políticos (1966), ninguém poderá ser perseguido ou molestado por suas opiniões, incluindo-se no direito à liberdade de expressão a liberdade de procurar, receber e difundir informações e ideias de qualquer natureza por qualquer meio de sua escolha. Tal direito, como todos os outros, não é absoluto, podendo estar sujeito a restrições legais, uma vez que qualquer propaganda em favor da guerra e qualquer apologia do ódio nacional, racial ou religioso que constitua incitamento à discriminação, à hostilidade ou a violência (art. 20).

O Art. 4 da Convenção Americana contra toda forma de Discriminção e Intolerância (OEA,2013) ${ }^{11}$, elenca que Os Estados comprometem-se a prevenir, eliminar, proibir e punir, de acordo com suas normas constitucionais e com as disposições desta Convenção, todos os atos e manifestações de discriminação e intolerância, inclusive:

i. apoio público ou privado a atividades discriminatórias ou que promovam a intolerância, incluindo seu financiamento; ii. publicação, circulação ou difusão, por qualquer forma e/ ou meio de comunicação, inclusive a internet, de qualquer material que: a) defenda, promova ou incite o ódio, a discriminação e a intolerância; b) tolere, justifique ou defenda atos que constituam ou tenham constituído genocídio ou crimes contra a humanidade, conforme definidos pelo Direito Internacional, ou promova ou incite a prática desses atos;

As campanhas eleitorais de 2018, ao pautarem temas

9 http://www2.stf.jus.br/portalStfInternacional/cms/verConteudo.php?sigla=portalStfJurisprudencia_pt_br\&idConteudo=185077\&modo=cms. Data de acesso: 22.11.2020.

10 A concepção de crimes contra a humanidade previstos no art. 6, c, do Estatuto do Tribunal de Nuremberg, procurava identificar algo novo, que não tina precedente especifico, ao menos, no passado das legislações internacionais. Sendo assim, representava um esforço inicial de tipificar o ilícito penal de forma inédita da dominação totalitária (assassinato, extermínio, redução a escravidão, a deportação contra a população civil por perseguição de cunho político, raciais e religiosa, as quais transcendiam de forma peculiar, os crimes de paz e guerra. Lafer, esina que o totalitarismo inaugura um novo formato, dentro da lógica do tudo é possível, onde os seres humanos são descartaveis, representando um enigma a ser decifrado, uma vez a personalidade humana passa a ser mero objeto (LAFER, 1988).

$11 \mathrm{https} / / /$ www.oas.org/en/sla/dil/docs/inter_american_treaties_A69_Convencao_Interamericana_disciminacao_intolerancia_POR.pdf. 
como liberdade de expressão, censura e discurso de ódio, evidenciaram a relação entre a palavra e o ato, no sentido de que certos discursos podem ser apontados como passíveis de punição, similarmente a um ato com consequências indesejadas pelo Estado e ou sociedade. Atos passíveis de punição jurídica e previstos em lei na sociedade moderna e contemporânea são os que podem ser enquadrados em algum código de lei.

Alguns casos, podem exemplificar os discursos de ódio, tais como, o caso Marielle Franco, em que um candidato arranca a placa com nome de rua com o nome da exvereadora, morta por ação das milícias no Rio de Janeiro; o caso do ex-Presidente Lula, numa cidade do Rio Grande do Sul, que culminou nos disparos de arma de fogo e agressões; o caso envolvendo, recentemente um grupo de enfermeiros que protestavam contra as mortes do COVID-19, sendo xingados por nacionalistas. Uma moça agredida a socos em Porto Alegre, por grupo de bolsonaristas, quando participava de um protesto pacifico. Uma jornalista nordestina que sofreu ameaça de estupro e morte, por simpatizantes de Jair Bolsonaro ${ }^{12}$.

O ponto central parte do seguinte questionamento: como a teoria Reichiana, analisaria os acontecimentos fatuais ocorridos e qual sua explicação para essa "psicologia das massas" e a proliferação dos discursos de ódio, no âmbito da sociedade brasileira, em face dessas manifestações que ocorreram com maior ênfase a partir das eleições de $2018^{13}$. Assim, adentrando na teoria de Reich, que experiência ensina que revelações dessa natureza não convencem as massas, e que, portanto, um questionamento apenas socioeconômico seria insuficiente para sua compreensão fenomênica.

Não seria mais pertinente perguntar o que está acontecendo com as massas, que as impede de poder reconhecer a função do fascismo? Não é possível compreender a economia sexual e os processos ideológicos da sociedade patriarcal sem ter em conta essa instituição. A psicanálise de homens e mulheres de todas as idades, países e classes sociais leva às seguintes conclusões: a combinação da estrutura socioeconômica com a estrutura sexual da sociedade e a reprodução estrutural da sociedade verificam-se nos primeiros quatro ou cinco anos de vida, na família autoritária. (REICH, 2001)

O problema prático da psicologia de massas é, portanto, a ativação da maioria passiva da população, seria na visão de Reich, que contribuiria para a vitória da reação política, e a eliminação das inibições que impedem o desenvolvimento do desejo de liberdade, proveniente da situação econômica e social. A energia psíquica das massas que assistem, entusiasmadas, a um jogo de futebol, não poderia reprimida se conseguisse libertar-se das suas cadeias e seguir os caminhos que conduzem aos objetivos racionais do movimento pela liberdade.

A sua origem está na vida emocional inconsciente, que começou por ser ignorada e cujas relações com aquela ideologia geralmente se prefere continuar ignorando. Mas uma análise das pessoas da classe média baixa não deixa quaisquer dúvidas quanto à importância da relação entre a vida sexual e a ideologia da "honra" e do "dever". Em primeiro lugar, a posição política e econômica do pai reflete-se nas relações patriarcais com os restantes membros da família.

O Estado autoritário, teria o pai como representante em cada família, sendo o principal elemento instrumental do poder. A posição autoritária do pai refletiria o seu papel político e revela a relação da família com o Estado autoritário. Essa posição de superior hierárquico (pai), no processo de produção, é por este assumida por todos membros da família, reproduzindo nos filhos (em especial do sexo masculino), a sua atitude de submissão para com a autoridade, resultando assim na atitude de passividade e obediência do indívido de classe média para com a figura do führer (REICH, 2001, p.97).

No Estado totalitário não há hierarquia de poder ou competência definidas com base na lei, e este amorfismo é o mecanismo para instrumentalizar a realização do princípio de liderança. O desejo da liderança, do chefe, pode encarnar-se, dependendo do momento, em qualquer dos múltiplos órgãos existentes ou criados pelo regime. Daí a insegurança e o isolamento dos indivíduos também no topo da estrutura do poder, obtidos inclusive com a cumplicidade da população, que é um dos ingredientes da gestão totalitária, pois através desta cumplicidade todos estão unidos por uma só culpa e incerteza (LAFER, 1988).

É importante sublinhar que, na visão de Reich, que o fator da inibição sexual constitui o elo da família autoritária e que o vínculo biológico original da criança com a mãe e da mãe com a criança forma a barricada contra a realidade sexual, levando a uma fixação sexual indissolúvel e a uma incapacidade de estabelecer novas relações. A base dos vínculos familiares seria o vínculo materno. As concepções de pátria e de nação são, no seu fundo emocional subjetivo, concepções de mãe e de família. Nas classes médias, a mãe é a pátria da criança, tal como a família é a sua "nação em miniatura.

Também é importante, vale destacar, que existe um vínculo existente entre o fascismo e as paixões mobiliadoras que plasmam a ação fascista: o nacionalismo apaixonado, aliada há uma visão maniqueísta da história como a batalha entre o bem e o mal, entre os puros e os corruptos, da qual a comunidade/nação é sempre vítima. O povo acaba de ser enfraquecido pelos partidos políticos, pelas classes sociais, pelas minorias assimiláveis, pelos grupos que vivem de renda,

12 https:/exame.com/brasil/apoiadores-de-bolsonaro-realizaram-pelo-menos-50-ataques-em-todo-o-pais/.

13 A sensação de deslimite desobstrui o potencial destrutivo de certas atitudes dentro da rede, constituindo o efeito nuvem da Internet no esconderijo preferencial para a maquiagem virtual a ações antissociais e antidemocráticas, manifestadas pelo bullying virtual, pela pedofilia transfronteiriça, pela facilitação do tráfico internacional de pessoas, pela divulgação de doutrinas neonazistas, discursos de ódio (hate speech), expressões de racismos e perseguições a minorias, pelo fortalecimento de redes de crime organizado, pela facilitação massiva da contrafação e da violação de direitos de propriedade intelectual. (BITTAR; ALMEIDA, 2019). 
debilitados por uma vida de excessiva facilidade.

Desse modo, e possível vislumbrar nos discursos de ódio, algumas premissas reichianas, em termos de realidade brasileira, tais como: a família como núcleo e base da sociedade, a ideia de nação, vinculado ao sentimento nacionalista/ pátria, a ideia de um líder autoritário, o qual conduzira essa nação e sociedade, devidamente unificadas, com intenso sentimento emocional no tripé (família, sociedade, nação), lastreada na base da estrutura hierárquica familiar, em que o nacionalismo do líder (herança nacional) que personifica a nação, encarnando esse sentimento psicológico das massas, contidos no ideário do fascismo nacional socialista alemão.

Sendo assim, a partir desses pressupostos reichianos, Hitler conseguiu atrair os trabalhadores e a classe média baixa, ao analisar os sentimentos nacionalistas do líder alemão, carregados de sentimentalismo pela morte da mãe e a revolta contra o pai, embora o respeito a sua autoridade. Por outro lado, a importância do Fuher, do ponto de vista sociológico e filosófico, resulta na verdade não somente em relação a sua personalidade, mas a importância na qual acaba conferindo as massas, ainda que num papel oposto aos trabalhadores (rurais e urbanos).

E na relação contraditória entre o "nacional, o socialismo e os trabalhadores", que Reich chegara há uma conclusão: quanto maior é o peso e a dimensão das camadas da classe média numa nação, tanto maior é a sua importância, como força social de ação decisiva, oscilando entre o capital e os trabalhadores. A explicação socioeconômica do ponto de vista marxista, acerca da consciência de classse não se sustentaria, quando por outro lado, o pensamento e a ação do homem são incoerentes com a situação econômica, ou seja, são irracionais.

\section{Conclusão}

A edificação da teoria Reichiana, contrapõe-se a teoria do materialismo dialético marxista, que tinha como premissa que a partir dos problemas ocasionadas pela infraestrutura (economia), seria possível que as massas, no caso o proletariado, enquanto classe de trabalhadores oprimidos, realiza-se o processo revolucionário de transformação contra a burguesia (classe dominante dos meios de produção). Na visão de Reich, o qual é signatário parcial do marxismo, essa teoria acabou ignorando o processo de irracionalismo das massas e a degeneração do processo autoritário do processo de revolução.

Wilhelm Reich prescinde da questão econômica enquanto elemento intrínseco e central a revolução de massas no processo de ruptura de poder e de uma determinada ordem social vigente, uma vez que nessa perspectiva não há relação direta entre o elemento econômico e a consciência social, pois ambos constituiriam realidades antagônicas entre si, em face do poder ligado ao sentimento psicológico que influenciaria diretamente nas massas a partir da estrutura autoritária familiar. Assim, as características do homem reacionário fascista estariam vinculadas há estreita ligação entre família, nação e religião.

Desse modo, a família, a religião e os sentimentos oriundo do seio familiar, detém papel importante para o exercício de dominação na psicologia das massas e consolidação no regime autoritário fascista, vinculados a ideia de nacionalismo, pátria e nação levam em conta a sua moral sexual, oprimida na infância, mas que irá reascender na vida adulta. Assim, os discursos ódios, na sociedade democrática brasileira são dotados de moralidade, irracionalidade, intimidação e ameaça com forte carga axiológica contra determinados grupos de indivíduos (negros, homossexuais, pobres, mulheres), uma vez que sua finalidade é a adesão das massas um elemento imprescindível para configuração do ideário autoritário, agora revestido de novas dimensões na era digital da sociedade de massas.

Por outro lado, a liberdade de expressão e comunicação, inclusive pela internet, garantida no âmbito dos tratados e convenções de direito humanos, pode ser limitada, quando ocorre a propaganda, a defesa, a justificação em favor das guerras ou genocídios, ou ainda, em razão da apologia ao ódio nacional, manifestações de ódio racial ou religioso, são passíveis de responsabilização pelo Direito Internacional.

No âmbito constitucional, tais práticas, não se coadunam com a $\mathrm{CF} / 88$, que tem como nota identificadora um estado democrático de direito, baseado numa sociedade livre, fraterna, pluralista e sem preconceitos, dentre outros objetivos, a promoção do bem-estar de todos sem preconceitos de raça, origem, sexo, idade e quaisquer outras formas de discriminação, especificando, ainda, a prática de racismo como crime inafiançável e imprescritível.

\section{Referencias}

ARENDT, H. Origens do Totalitarismo. São Paulo: Companhia de Bolso, 2013.

BITTAR, E.; ALMEIDA, G.A. Curso de Filosofia do Direito. São Paulo: Atlas 2019.

BOBBIO, N. Dicionário de política. Brasília: Universidade de Brasília, 1998.

BOBBIO, N. A era dos direitos. Rio de Janeiro: Elsevier, 2004.

KONDER, L. Introdução ao Fascismo. São Paulo: Expressão Popular, 2009.

LAFER, C. A reconstrução dos Direitos Humanos. Um diálogo com o pensamento de Hannah Arendt. São Paulo: CIA das Letras, 1988.

LAFER, C. A Internacionalização dos direitos humanos. Constituição, racismo e relações internacionais. Barueri: Manole, 2005.

KANT, I. A paz perpétua: um projecto filosófico. Covilhã: Universidade da Beira Interior Covilhã, 2008.

MARX, K.; ENGELS, F. Manifesto do Partido Comunista. São Paulo: Expressão Popular, 2008.

MENDES, G. Curso de Direito Constitucional. São Paulo: Saraiva, 2017.

NADER, P. Filosofia do direito. Rio de Janeiro: Forense, 2018. 
OLIVEIRA, D.M.O.; CRUZ, M.H.S. Sobre a Psicologia de Massas do Fascismo de W. Reich. Rev. Psicol. Saúde, v.1, n.1, p.70-76, 2009.

ORWELL, G. O que é Fascismo. São Paulo: Companhia das Letras, 2017.

PIOVESAN, F. Direitos humanos e o direito constitucional internacional. São Paulo: Saraiva, 2013.

RAMOS, D.O. Caminhos para uma reflexão sobre discurso de ódio, liberdade de expressão e pensamento-cálculo. Liberdade de Expressão: Questões da atualidade. Revista da USP, 2019.

RAMOS, A.C. Curso de direitos humanos. São Paulo: Saraiva, 2020

REICH, W. Psicologia de massas do fascismo. São Paulo: Martins Fontes, 2001.
SARLET, I. Curso de Direito Constitucional. São Paulo: Saraiva, 2015 .

SARLET, I. Curso de direito constitucional. São Paulo: Saraiva Educação, 2019

WEINMANN, A. Uma contribuição à história do movimento psicanalítico: a trajetória de Wilhelm Reich. Psicol. Cienc. Prof., v.22, n.3, 2002.

SILVA, T.M. O discurso do ódio como instrumento balizador e limitador da liberdade de expressão. Rio de Janeiro: Escola de Magistratura do Estado do Rio de Janeiro, 2016.

SILVA, I.G.R.; SILVA, J.C.S. Liberdade de expressão e seus limites: o discurso de ódio é tolerável? VirtuaJus, v.3, n.5, p.255273, 2018. 